\title{
A geogenic approach for the Radon monitoring and the exposure assessment at a regional scale: The results of the Rad_Campania project
}

\author{
Simona Mancini ${ }^{1,2}$, Michele Guida ${ }^{1,2}$, Albina Cuomo ${ }^{3}$, and Domenico Guida ${ }^{3,4}$ \\ ${ }^{1}$ Department of Computer Engineering, Electrical Engineering and Applied Mathematics (DIEM), \\ University of Salerno, Fisciano, 84084, Italy \\ ${ }^{2}$ Laboratory of Environmental Radioactivity "Ambients and Radiations" (Amb.Ra.), \\ University of Salerno, Fisciano, 84084, Italy \\ ${ }^{3}$ Department of Civil Engineering (DICIV), University of Salerno, Fisciano, 84084, Italy \\ ${ }^{4}$ interUniversity Centre for the Prediction and Prevention of Major Hazards (CUGRI), \\ University of Salerno, Fisciano, 84084, Italy
}

Correspondence: Simona Mancini (smancini@unisa.it)

Received: 31 May 2020 - Revised: 14 September 2020 - Accepted: 17 September 2020 - Published: 5 November 2020

\begin{abstract}
The aim of this paper is to analyse and discuss the results of the regional program Rad Campania for the monitoring and the assessment of the radon risk. An innovative methodology, based on a geogenic approach, was developed, supported by a comprehensive campaign of radon measurement performed in soil gas, natural waters, drinking natural water samples and indoor air. Data refer to field measurements carried out in three provinces of the Campania Region (Italy): Salerno, Avellino and Benevento. The programme was completed with the main purpose to investigate the peculiarities of the radon issue at a provincial scale and to redact a map of the radon potential from soil as a tool for authorities to recognise critical areas ("Radon prone areas") to monitor. Since the experience demonstrates that the high radon potential from soil is not indicative of high indoor radon concentrations, in this paper the authors have tried to identify a possible general correlation between geological features of the soil and structural characteristics of the buildings, elaborating more in depth all data collected. The main purpose is to categorize and analyse the performance of different kind of construction, typical of the local area, in order to develop, in a future work, an indicator of the building performances as a useful tool, for authorities, to recognise constructions potentially more exposed to high indoor radon activity concentrations. Results and perspectives have been discussed.
\end{abstract}

\section{Introduction}

Since its very first moments on the Earth, Mankind has been continuously exposed to ionizing radiations from environmental radioactivity, consisting in three kinds of contribution: cosmogenic, primordial and anthropogenic. Among them, the one produced by naturally occurring primordial sources provides the largest percentage to the human exposure. The most important primordial source is constituted by radionuclides, such as ${ }^{40} \mathrm{~K}$ and the uranium and thorium decay families $\left({ }^{238} \mathrm{U},{ }^{232} \mathrm{Th}\right.$ and ${ }^{235} \mathrm{U}$ series). Many of the intermediate radioisotopes in these chains are metals and chemically reactive. For this reason, once formed by the predecessor's decay, they remain confined in the rocks, where they were generated, unless dispersed into the environment due to the erosion mechanisms made by weathering processes.

The only exception is represented by radon, the heaviest chemical noble element, which occurs in the gaseous state at Standard Temperature and Pressure (STP) conditions and naturally does not create chemical bonds. It tends, therefore, to migrate within the rock materials in the soil, where it has been formed (emanation process), and transported in the near-surface soils by fluid carriers (water, air, $\mathrm{CO}_{2}, \mathrm{CH}_{4}$ ), through advective and diffusive displacements, favoured by the soil mechanical characteristics, (porosity, structure and particle size) and the environmental conditions reaching the atmosphere (exhalation process) or spatial locations distant 
from the source (Hosoda at el., 2012; Stavitskaya et al., 2019).

The most abundant naturally occurring radon isotope is ${ }^{222} \mathrm{Rn}$ (half-life of 3.82 days) and, also from the human health protection point of view the most relevant together with its short-lived alpha emitting progeny. In fact, regarding its relevance as hazard for humans, this radionuclides easily bind to the aerosol present in the indoor air, and, once inhaled, deposit on the bronchial tree, where emitting alpha ionizing radiation turns to be harmful for basal cells of the bronchial epithelium, critical targets for any cancerous changes (Ismail and Jaafar, 2011).

Inhalation of radon and its decay products contributes to about the $50 \%$ of the individual annual dose due to natural radioactivity and is considered the most important cause of lung cancer, after smoking (WHO, 2009). Because at the moment there is no known threshold value below which radon exposure carries "zero Risk" of lung cancer to humans, there is a general interest and concern to minimize the exposure of the population to levels as low as possible.

Besides its relevance as a harmful hazard for people health, radon has such peculiar physical features that make it extremely useful in environmental and earth science (Baskaran, 2016). Radon assessment has been used like one additional tool (seismic precursor) to register the possible occurrence of seismic events by means of its possibly occurring activity concentration anomalies (Buttafuoco et al., 2007; Iovine et al., 2018), associated to land movements due to volcanic eruptions and occurring in geothermal areas; in fact, gases can be released can be generated and pressurized by hot regions such as volcanos and stress can be generated by the build-up of strains that precede earthquakes and volcanic eruptions (De Lauro et al., 2009; Falanga et al., 2019).

The main exposure to high radon activity concentrations generally occurs in basement or/and poor ventilated environments, where, once exhalated in the air from a source (soil is the most relevant one), radon can accumulate reaching levels harmful for the occupants. Building materials play a secondary role and in some cases water and gas supplies represent a further non-negligible source. Outdoor radon level is in the range of $5-15 \mathrm{~Bq} / \mathrm{m}^{3}$ range, due to the effectiveness of mixing processes in the atmosphere (Nero, 1989; Nero and Nazaroff, 1984, 1988, UNSCEAR, 2000).

But, even in presence of a relevant source of radon production, the total indoor activity concentration mainly depends on the ability of the gas to penetrate inside a closed environment. Radon migration depends on two independent processes: the advection mechanism driven by a pressure gradient and the molecular diffusion, due to gas concentration gradient. The parameters affecting the transport process are essentially the diffusion coefficient and the permeability of the medium. Instead, the entry into the building depends not only on the transport phenomenon but also on the interface properties between the soil, where the transport occurs and the internal environment. Therefore, the accumulation inside the building is the result of the balance between the entry rate and the gas removal rapidity (essentially related to the ventilation rate and the radioactive decay).

So, if the relevant influence of the soil on radon concentrations detectable in buildings is more than evident, it is also clear that building materials (influenced by the radium content, structure and water content) also can play a strategic role due to the exhalation phenomenon from them. It is estimated, in fact, that for a single standard house in masonry and in a temperate climate, the radon coming from the soil beneath the basement, constitutes $60 \%$ of the total, while the diffusion from building materials and the infiltration of radon with the extract air, can play a not negligible role (superior to $20 \%$ and $18 \%$ respectively); other indoor radon sources like water and natural gas supplies turn out to be relatively less important.

For such reasons radon activity concentrations are expected to decrease on the upper floors where the largest contributions is expected to be from building materials or, sometimes, from particular pathways of air circulation (stairwell, elevator, cables...) inside the building which starting from the ground can reach the upper floors (chimney effect).

All this assumed, the relative contributions of the various sources of radon and parameters affecting the processes are strongly variable from one building to another. Nevertheless, it could be a good starting point to analyse all data collected in a specific area to identify firstly the peculiar geological features of the local area and then categorize the buildings, according the traditional local system, in order to recognize the more exposed type to the problem of the radon accumulation (Mancini et al., 2014a).

The interest to identify buildings vulnerable to radon accumulation, because of its impact on people health, is, also, moved by the requirements of the European Directive 2013/59/EURATOM, which states all the sources of radon entry into buildings have to be considered and taken into account under a point of view truly interdisciplinary. In the same spirit expressed by the Directive, the Joint Research Centre (JRC) of the European Commission has been working to the project of a European Atlas of Natural Radiation. The Atlas is a collection of maps of Europe displaying the levels of natural radioactivity caused by different sources such as indoor radon, cosmic radiation, terrestrial gamma radiation, terrestrial radionuclides in soil and bedrock (Tollefsen et al., 2017; Ciotoli et al., 2017; Watson et al., 2017; Bossew et al., 2020).

For such reasons an Interdisciplinary Strategic Programme of Applied Research for the Assessment of Naturally Occurring Radioactive Materials in Natural and Anthropic Environments, called RAD_CAMPANIA, with particular attention to radon, has been started in Italy at the University of Salerno, in collaboration with the interUniversity Centre for Applied Research on the Prediction and Prevention of Major Hazards (CUGRI), and the Regional Agency for the Environ- 
mental Protection of Campania (ARPA Campania) (Guida et al., 2013; Cuomo et al., 2015; Mancini et al., 2018).

This 10 years work, so far, has shown that the environmental monitoring in workplaces or housings, can, no more, be limited to integrated measurements, but must be necessarily capable to identify which is the main source (soil, building material, water or natural gas) responsible for the accumulation of indoor Radon. This is needed in order to design and perform the most appropriate mitigation remedies, in new and existing buildings, reducing the maximum levels to the reference limits prescribed by the legislation and compliant with the requirements of energy-efficient modern buildings, as it has been underlined by Yarmoshenko et al. (2014).

RadCampania project produced numerous and different outcomes, from the study of the interactions between natural water bodies (surface and groundwater) to the modelling of the radon entry and accumulation in buildings. In this work the aspects related to geogenic feature of the soil and characteristics of buildings are discussed and analyzed.

Thanks to the adaptability and flexibility of the developed methodology the procedure is appropriate in any areas and results can be considered as valid support in areas with similar geological features, instead.

\section{Materials and methods}

\subsection{Study area}

The geological structure of the Italian territory comprises recent volcanic rocks, granitic areas, and high permeability soils located in the vicinity of seismic faults. These features suggest the existence of radon-prone areas (Bochicchio et al., 1996), which are prescribed by the still effective Italian regulation D.Lgs. n.241-2000, implementing the old EU Directive 1996/29 about the protection of public and workers health against the risks associated to ionizing radiations.

Among the Italian regions, Campania exhibits all those features in its territory, covering a total area of $13590 \mathrm{~km}^{2}$, including the largest Italian province, the province of Salerno $\left(4954 \mathrm{~km}^{2}\right)$ and, showing, in addition the highest population density in Europe, 2671 people per $\mathrm{km}^{2}$ w.r.t. the national average value of 199.8 people $/ \mathrm{km}^{2}$ and the European average value of 34 people $/ \mathrm{km}^{2}$.

From a geological point of view, the territory is one of the places in the world where a large variety of geological environments are present in a narrow, highly inhabited area (for an extensive description see Cuomo, 2012; Vitale and Ciarcia, 2018).

The physiography of the Campania region landscape is very complex, depending by geology, morpho-structural setting and morphogenesis. In general, three sectors can be defined: coastal plains (about $25 \%$ in area), filled by fluvial and marine clastic successions, marly-clayey, anti-Appenine hilly landscape $(31 \%)$ and carbonate and terrigenous mountain landscape $(44 \%)$.

The region corresponds, geo-tectonically, to the periTyrrhenian sector of the Campano-lucanian Arc within the Southern Appennine Chain. This one represents a segment of a larger fold-and-thrust belt built up in Central Tethys between late Cretaceous and Pleistocene, as consequences of interaction between the European and African plates, spreading of the Tyrrhenian oceanic basin and anti-clockwise rotation of the orogenic front. Due to long-time and complex litho-genetic history, tectono-sedimentary events and orogenetic displacements, several litho-stratigraphic units, stacked in form of normal overthrusts and/or irregular sequence, can be distinguished.

The Internal Units, Mesozoic to Tertiary aged, are made up at the base prevalently by marly, varicoloured clay, in oceanic plain sedimentary facies, passing above to calcarenites, calcilutites, often cherty, argillites, sandstones and rare conglomerate deposited in a distal turbidite basin. The External Units are constituted mainly by neritic, carbonate sediments of Mesozoic and Tertiary age which show sedimentary environments going from the shallow water carbonates with back-reef facies to slope and deep water carbonates. These units form the main mountainous massifs of Campania region located both inland and coastal areas; they constitute the bedrock of major karst massifs in the Matese M.nts, Camposauro-Taburno M.nts, Avella-Partenio M.nts, Sorrento Peninsula, Picentini M.nts, as well as in the Cilento. The Lagonegro Units are made up of cherty limestones at the base and marly clayey at the top, likely deposited in a deep marine basin, outcrops exclusively along the axis of Apennine Chain. The Apulia Units represent the remnants of Apulia Foreland, in progressive lowering under the Foretrough and Chain by deep normal and listric faults. In disconformity, there are the Neogenic Sinorogenic Units, represented by several terrigenous formations and units referred to Miocene-Pliocene age, lying on previous units and in the Bradanic Forethrough. They are mostly in turbidite facies, from wild-flysch to submarine fan sedimentary characters. For instance, Cilento Group is one of these units, which is the most widespread unit in the homonymous area and along the corresponding coast; a minor unit outcrops in Sorrento Peninsula. Surrounding the Somma-Vesuvius volcanic complex and Phlaegrean Phields, near Naples city and Ischia and Procida volcanic islands, large surfaces are covered by volcanic formations and volcano-clastic deposits, Pleistocene in age . They are known as the peri-Tyrrhenian volcanism due to the deepest crossing normal faults of the Campania Plain Graben.

The Quaternary Post-orogenic Units include all the continental, transition and marine clastic sediments, deposited after the final emersion of Apennine Chain, from Late Pliocene to Early Pleistocene and Holocene. They are represented by aeolian, fluvial, piedmont, lacustrine and travertine deposits along the river valleys and coastal plains. Such units 
can show intercalation of the products of Vesuvian and Phlaegrean volcanic activity, previously considered (Cuomo, 2012).

Because of this soil characteristics, the Campania region is characterized by an indoor Radon (arithmetic) mean activity concentration value, $95 \mathrm{~Bq} / \mathrm{m}^{3}$ higher than the national average, around $70 \mathrm{~Bq} / \mathrm{m}^{3}$ (Bochicchio et al., 1996). At first instance these indoor Radon values in Campania can be reasonably expectable due to the above explained geological features and, in addition, the extensive use of stones of volcanic origin (yellow tuff, grey tuff, etc.) in the traditional building construction systems.

\subsection{The hierarchical multi-scalar geogenic approach}

The RAD_Campania Project was aimed to the construction and the application of an innovative adaptive geogenic methodology for the estimation of the radon potential, integrated in a GIS-based environment. This program adopts a multiscale and hierarchic approach, widely used in environmental planning and landscape ecology (Blasi et al., 2007)

In the following there will be briefly shown the main assumptions and preliminary results of the "Radon-prone Areas" Sub-project developed according to the directions of the Radon National Plan (MDS Italian Ministry of Health, 2002).

The adopted approach exploit techniques of differentiated analysis at different scales of territorial analysis, which are interactive and progressively more specific and in depth: from the zoning at a regional scale to the physicalmathematical modelling at a site scale, adopting an approach called "Hierarchical and Multi-scale Areas Zoning". It is finalized to the individuation and classification of the Radon-prone Areas, organized in coherently hierarchical terms (Fig. 1).

The Regional Level of analysis and mapping provides specific tools, at the scale $1: 250000$, suitable for the regional planning.

The Provincial Level, mapping at the scale $1: 100000$, can be suitable and useful for the sub-regional territorial planning.

At the District level, the scale of analysis between $1: 50000$ and $1: 25000$ is suitable for Inter-municipal Plans i.e. the Territorial Planning of aggregated municipality (Strategic Town Plans) or for epidemiological strategies by the Local Sanitary Authorities.

The Zone level of analysis represents the Radon-soil gas spatial distribution at the scales of $1: 5000-2000$ and turns to be useful for a Municipal Town Planning. At least, the Site one is suitable for Executive Planning, at the scale $1: 2000$ and for Radon-soil gas and Indoor Modelling.

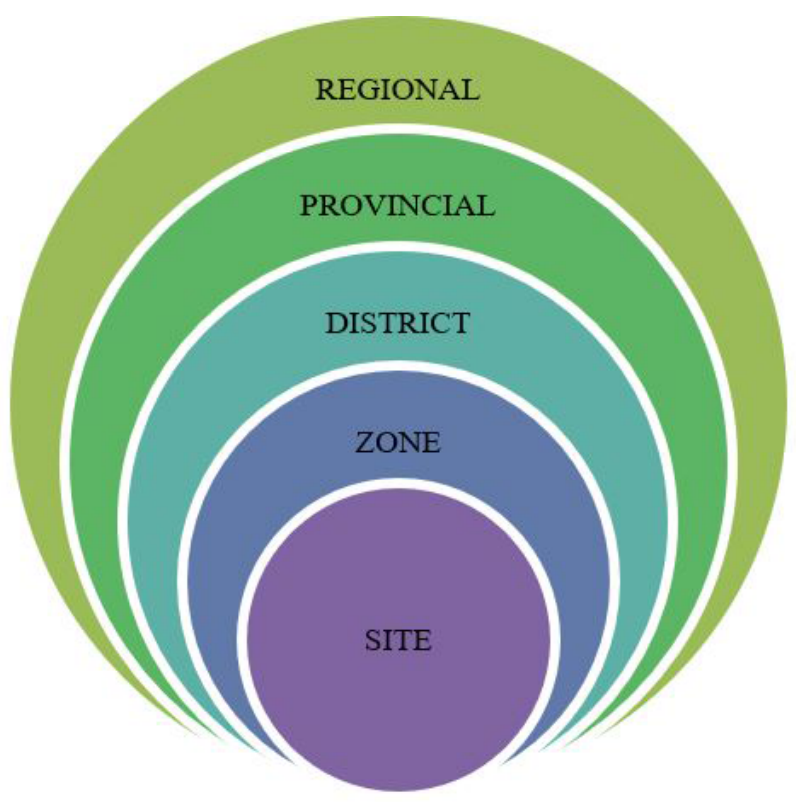

Figure 1. Hierarchical Multi-scale Levels for the Radon-prone Areas in Campania Region.

\section{The analysis at regional and province level}

The preliminary map, GIS based, of the Radon-prone Areas, at regional level, has been made through two operative steps:

- the geological analysis of regional synthesis, with the individuation and delimitation of the Lithological Systems (Blasi et al., 2007), characterizing the main geological formations outcropping in the Campania region.

- the complete bibliographical analysis containing references on radon-soil gas-geology correlations, then applied to the Campania region geological setting.

This procedure produced only an indicative, but not an operative tool for planning purposes.

At province level, instead, a more articulated methodology of analysis has been implemented, in order to give a greater detail setting, considering, besides the lithology, the main recognized factors contributing to radon exhalation from soil.

The procedure starts from the assumption, acquired in the specific scientific literature, that the geological factors, increasing the probability that an area can show higher levels of Radon-soil gas than the average ones (Schuman and Owen, 1988).

The methodology, developed in Guida et al. (2008), follows partly the indirect procedures in the Radon Soil Exhalation Potential (PERS) Project, realized by the former Italian National Agency for Environmental Protection (ANPA, 2000), adapting them to the Campania region and integrating the rules elaborated by Wiegand for compiling of the Radon Guide Lines in Germany (Wiegand, 1996, 2001), and by the 


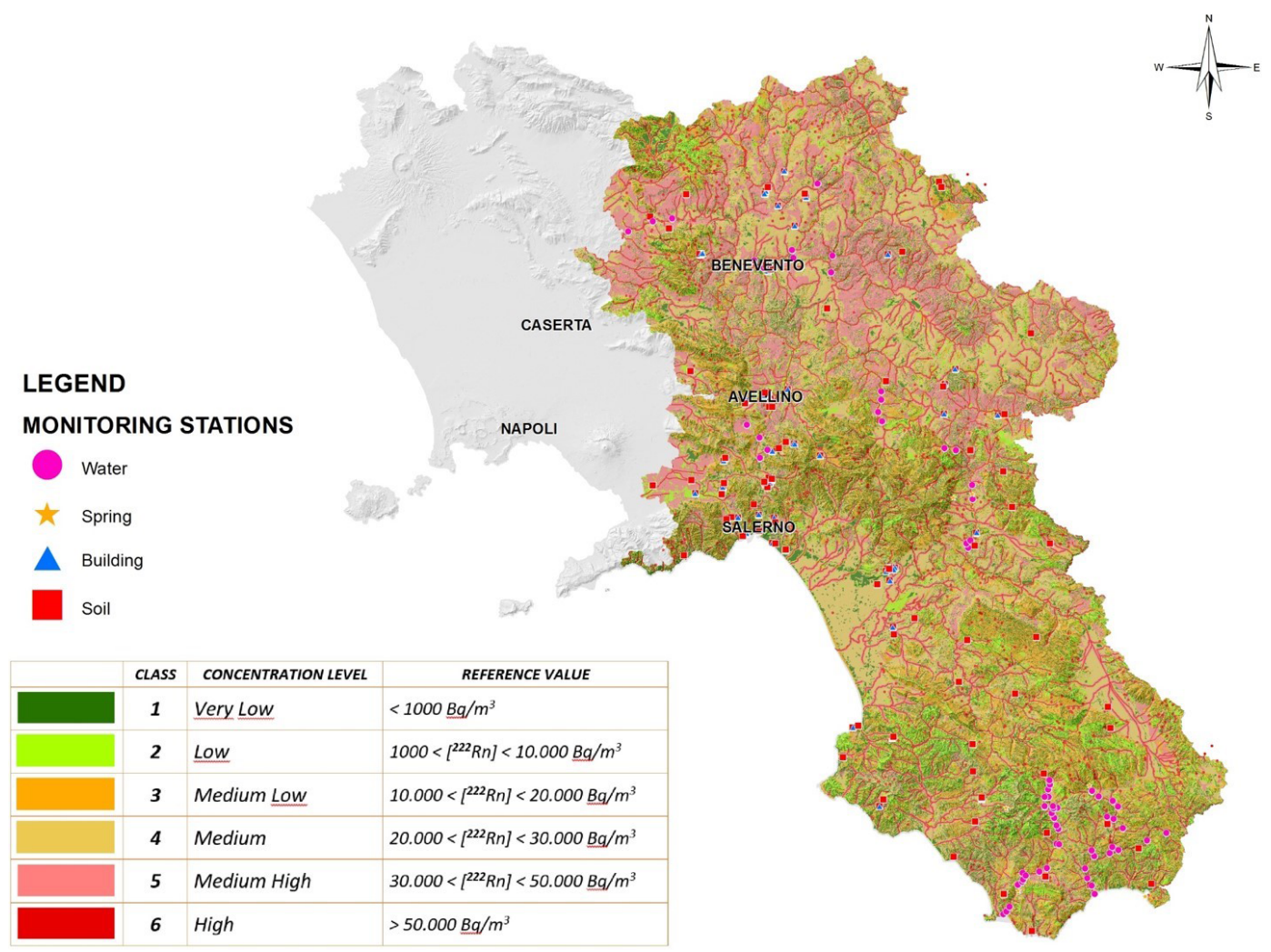

Figure 2. Campania radon potential map (including the province of Salerno, Avellino and Benevento).

Illinois Emergency Management Agency, for the compiling of the Status Report Radon in the Illinois State, USA (IEMA, 2006).

The application of the methodology allowed to set up a preliminary Map of the Radon-Prone Areas built up by the following steps: (i) "geology-based" correlations from more specific bibliography; (ii) more geological detail than the one at the regional level, with the individuation and the mapping of the Lithological Complexes; (iii) setting from experimental measurements of radon soil-gas in different sample sites, located in lithological complexes representative of the provincial territory; (iv) compiling of a Map of interpretative synthesis, obtained from the spatial analysis rules, applied in GIS environment, taken into account the specific contributes to the exhalation deriving from various factors (geology, geomorphology, hydrogeology, vegetation, etc.) and progressive calibration of the weighted values by the real data acquired from the in situ measurements, opportunely gathered and managed in an appropriate Relational Database.

The general procedure for the compiling of the Radonprone Areas Map is based on the Factor Rating Method, implementing a GIS_Raster procedure (Biallo, 2005) and adopting a "cascade" criteria from progressive analysis of the basic factors and successive steps, according the procedure deeply described in Guida et al. (1994).
At the end, the radon potential map has been realized, representing the aggregated results (Fig. 2) (Cuomo et al., 2015).

After the conclusion the program, more than 500 measurements of radon activity concentration in soil-gas, water (natural streams and springs) and buildings have been performed from the end of February to July 2010.

The RAD_Campania survey has involved a total of 96 sampling sites or measurement stations, distributed according to different geological characteristics, with a density of the measurements grid per province proportional to the homogeneity of the geological features and the territorial extension of the province itself.

The final map classifies the areas in six classes, from 1 (very low) to 6 (very high), highlighting a progressively higher radon potential hazard.

The investigation of the provinces of Napoli and Caserta, where the geology and geophysics, the tectonics, the petrology, the lithospheric structure beneath the volcanic systems turn out to be extremely complex, for the presence of many different volcanic systems a variegated kind of occurring geodynamical phenomena (Vitale and Ciarcia, 2018), strictly connected with the radon presence in the territory, were not included in the RAD_CAMPANIA project. 


\subsection{Experimental set up}

Radon activity concentration measurements have been performed both on-site and in the Laboratory of Environmental Radioactivity "Amb.Ra." of the University of Salerno, ISO 9001:2015 certified, with the logistics support provided by the interUniversity Centre for Applied Research on the Prediction and Prevention of Major Hazards (CUGRI) and in collaboration with the Regional Agency for the Environmental Protection of Campania (ARPA Campania).

In order to accomplish the tasks of the project, it has been used a unique highly versatile radon measurement facility system, able to perform radon measurements in different environmental matrices (soil-gas, water, indoor-air), guaranteeing coherent, harmonized standardized measurement methods both in-situ and in the laboratory, conformally to international ISO Standards. Among the different available experimental instruments the choice to adopt the alpha spectrometry technique of the radon short-lived progeny by means of a continuous radon monitor, is related to the ability to observe the variation of "radon levels" during the measurement. Moreover, such devices are the unique which can be easily exploited both on-site and in the laboratory providing, at the same time, low background and high sensitivity.

In particular, it has been employed the Durridge RAD7 (2012, Durridge Company, Inc., Bedford, MA, USA), a solid state ion-implanted silicon semiconductor alpha detector, converting alpha radiation directly to an electrical signal, with two important advantages: ruggedness and the ability to electronically determine the energy of each alpha particle. This makes it possible to tell exactly which isotope (polonium-218, polonium-214, etc.) produced the radiation, so that one can immediately distinguish old radon from new radon, radon from thoron, and signal from noise. This technique, known as alpha spectrometry, has a great advantage in sniffing, or grab-sampling, applications assuring a nominal sensitivity, in sniff mode, of $0.0067 \mathrm{cpm} /\left(\mathrm{Bq} / \mathrm{m}^{3}\right)$, while in normal mode $0.013 \mathrm{cpm} /\left(\mathrm{Bq} / \mathrm{m}^{3}\right)$.

Besides the solid-state alpha detector, RAD7 consists of a 0.7 L hemispherical cavity, coated on the inside with an electrical conductor. To perform field or laboratory measurement the instrument needs to be connected to special accessories according the user manuals. In particular, to perform field measurements in the soil, a soil probe (a steel pipe with $8 \mathrm{~mm}$ inner diameter, $15 \mathrm{~mm}$ outer diameter and $110 \mathrm{~cm}$ length) was inserted down to a minimum depth of $0.7 \mathrm{~m}$. The inlet port of RAD7 was connected to the sampling tube outlet using vinyl flexible tubes through a dust filter and an inlet filter (pore size $1 \mu \mathrm{m}$ ) which prevented dust particles and radon progeny from entering the chamber. The performing of measurements in the indoor air, does not need, instead, special complements. The adopted configuration of the instrument to perform measurements in soil gas and indoor air is reported in Fig. 3 (the configuration for measurements in water is omitted as it has been already described extensively in pre-
Table 1. Measured values of radon activity concentrations in soilgas.

\begin{tabular}{lcrccr}
\hline \multirow{2}{*}{ Province } & Sites & \multicolumn{4}{c}{ Radon activity concentration $\left[\mathrm{Bq} / \mathrm{m}^{3}\right]$} \\
\cline { 3 - 6 } & No. & mean & minimum & maximum & $\mathrm{SD}(\sigma)$ \\
\hline Benevento & 21 & 7845 & $<$ MDA & 28700 & 1131 \\
Avellino & 26 & 15011 & $<$ MDA & 68000 & 880 \\
Salerno & 49 & 18379 & $<$ MDA & 90000 & 1479 \\
\hline Total & 96 & 13745 & $<$ MDA & 90000 & 1479 \\
\hline
\end{tabular}

Table 2. Measured values of radon activity concentrations in indoor air.

\begin{tabular}{lcrcrr}
\hline Province & Sites & \multicolumn{4}{c}{ Radon activity concentration $\left[\mathrm{Bq} / \mathrm{m}^{3}\right]$} \\
\cline { 3 - 6 } & No. & mean & minimum & maximum & SD $(\sigma)$ \\
\hline Benevento & 21 & 84 & $<$ MDA & 204 & 29 \\
Avellino & 26 & 327 & $<$ MDA & 5930 & 92 \\
Salerno & 49 & 160 & $<$ MDA & 1610 & 67 \\
\hline Total & 96 & & $<$ MDA & 5930 & 92 \\
\hline
\end{tabular}

vious papers focusing only on water measurements and data acquired, Guida et al., 2013, 2015).

The monitoring plan, the preparation of instruments, the collection samples and the data recording process were achieved according the internal standardized procedure of the Laboratory Ambient and Radiations. Measurement protocols, for each environmental matrix (soil, water, air) have been provided by the factory, instead.

All the campaigns have been conducted by means of no. 3 calibrated RAD7 instruments, one completely dedicated to radon-soil gas, one for indoor air and one for radon-in-water measurements.

\section{Other data}

For each measurement, geographic coordinates, altitude and meteorological data were collected, as the building characteristics, floor and lithological characteristics of the underlying soil if available. During the campaign a survey was conduct according a questionnaire suggested by the guidelines integrated in the national radon plan.

\section{Data results}

Once collected all data and information, the first step was to categorize the complete dataset (Tables 1-2). Note a the different number of investigation sites per province because it is proportional to the extension of the territory and the presence of a great variability of the soil (non-homogeneous geology). So, the larger province of Salerno was investigated with a greater number of investigations in the soil and indoor air. 

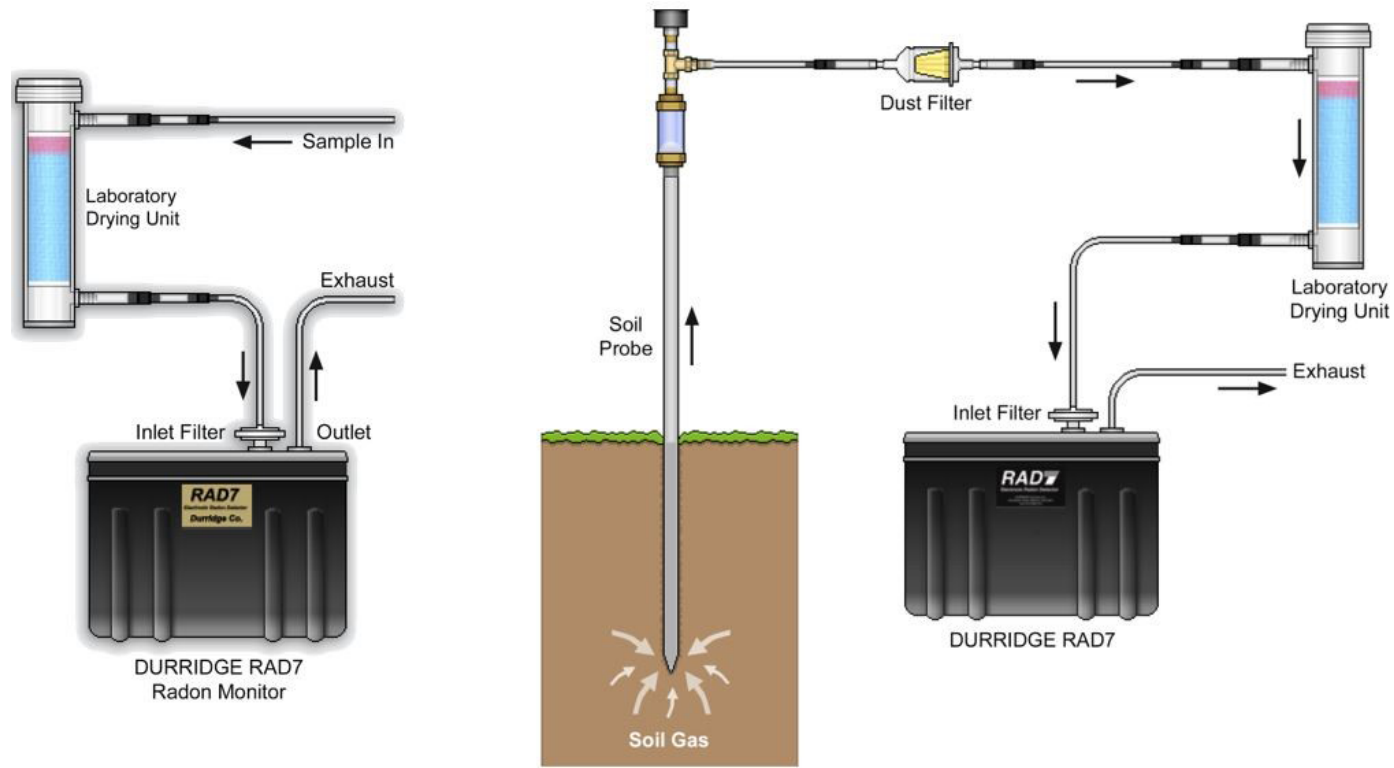

Figure 3. RAD7 Normal Configuration for indoor Radon and Soil Gas Probe configuration.

Table 3. Mean value of radon activity concentrations in indoor air according the zone-type.

\begin{tabular}{lccr}
\hline Zone & Sites & \multicolumn{2}{c}{$\begin{array}{c}\text { Radon activity } \\
\text { concentration }\left[\mathrm{Bq} / \mathrm{m}^{3}\right]\end{array}$} \\
\cline { 3 - 4 } & No. & mean & $\mathrm{SD}(\sigma)$ \\
\hline urban & 55 & 209 & 54 \\
metropolitan & 14 & 268 & 59 \\
rural & 27 & 101 & 42 \\
\hline
\end{tabular}

Table 4. Mean value of radon activity concentrations in indoor air, measured at the basement floor of buildings, according the foundation type.

\begin{tabular}{lrrr}
\hline Foundation's type & Sites & \multicolumn{2}{c}{$\begin{array}{c}\text { Radon activity } \\
\text { concentration }\left[\mathrm{Bq} / \mathrm{m}^{3}\right]\end{array}$} \\
\cline { 3 - 4 } & No. & mean & $\mathrm{SD}(\sigma)$ \\
\hline Slab on grade & 42 & 344 & 66 \\
Submerged/flush crawl space & 48 & 73 & 42 \\
Strap/single spread footing & 6 & 55 & 20 \\
\hline
\end{tabular}

Instead, in order to elaborate more in-depth data pursuing the aim to investigate the main features responsible of the accumulation of radon indoor, the analysis was restricted to data related to indoor radon and the soil. Data related to water were not considered because not significative for this purpose.
Table 5. Mean value of radon activity concentrations in indoor air at the basement/ground floor vs. first floor.

\begin{tabular}{llcr}
\hline Floor & Sites & \multicolumn{2}{c}{$\begin{array}{c}\text { Radon activity } \\
\text { concentration }\left[\mathrm{Bq} / \mathrm{m}^{3}\right]\end{array}$} \\
\cline { 2 - 4 } & No. & mean & $\mathrm{SD}(\sigma)$ \\
\hline Basement/ground & 92 & 190 & 50 \\
first & 4 & 188 & 59 \\
\hline
\end{tabular}

So, this kind of analysis involved 192 data, 96 in the soil gas and 96 in buildings performed in the province of Avellino, Benevento and Salerno. Soil gas measurements were performed in the nearby of the investigated building in order to then verify a possible correlation between the geogenic prognosis and the actual measured indoor values. In fact, if radon concentrations in soil gas can be regarded as a natural hazard parameter which is independent on construction type, state and age of existing houses, indoor radon instead is very influenced by the building-specific characteristics lifestyle of inhabitants.

As previously stated, the aim of this final report is to evaluate possible correlation between indoor radon concentration and other features. For this kind of analysis, data were catalogued according to the zone (urban, metropolitan, rural), the type of foundation (direct contact, crawl space, private, upper floor) and the type of material (reinforced concrete, tuff, stone) (Tables 3-5) and, then, combined according to the main materials used for walls and the type of foundation, Table 6. 
Table 6. Mean value of radon activity concentrations in indoor air at the basement ground floor grouped according the material of the wall and the foundation type.

\begin{tabular}{llrr}
\hline Material (walls) & Foundation type & $\begin{array}{r}\text { Radon activity } \\
\text { concentration }\left[\mathrm{Bq} / \mathrm{m}^{3}\right]\end{array}$ & $\begin{array}{r}\mathrm{SD}(\sigma) \\
{\left[\mathrm{Bq} / \mathrm{m}^{3}\right]}\end{array}$ \\
\hline Concrete & Slab on grade & 227 & 68 \\
Concrete & Submerged/flush crawl space & 53 & 31 \\
Concrete & Strap, single spread footing & 25 & 41 \\
Tuff or natural stones & Slab on grade & 504 & 78 \\
Tuff or natural stones & Submerged/flush crawl space & 150 & 82 \\
Tuff or natural stones & Strap/single spread footing & 81 & 31 \\
Brick & Slab on grade & 64 & 24 \\
\hline
\end{tabular}

\section{Data discussion}

Results confirm how urban areas are more exposed to the indoor radon accumulation, maybe because of the outdoor air pollution people are not accustomed to ventilating naturally their house and tends to live in well closed and isolate flats. So, in urban areas the problem is mostly attributable to behavioural factors related to the city lifestyle.

As regards the structural features it is not possible to define sharply a type of foundation or material which increase with evidence indoor levels. In fact, even if tuff is a material with higher radium content than others, data show how higher concentrations were revealed in buildings made in concrete and with aerated foundation (crawl spaces). This result highlights how the maintenance of the interface soilbuildings (in terms of presence of cracks) plays the most important role in the accumulation phenomena. This consideration could be also confirmed by the comparison of Tables 3 and 4. As it could be observed (Tables 1-2) the province showing a higher radon concentration from soil (Salerno) is not the same showing higher indoor radon concentrations (Avellino). The maintenance of a buildings is also connected by the socio-economic and cultural context. For example, detached and semidetached houses show generally a bad maintenance state instead of multifamily building because of the refitting costs.

At least another important consideration could be done in relation to the obvious reducing of the indoor radon levels from lower to upper floor. As expected, the contribute of the main source of radon, the soil, tend to decrease dramatically (in our case less than 4 times) because of the ventilation exchanges indoor-outdoor and indoor-indoor.

Regarding the contribution to the indoor radon activity concentrations provided by the building materials its direct evaluation from the activity of the naturally occurring radionuclides contained in walls, ceilings and structural elements, which is expressed usually, both in the regulatory bodies and in the scientific literature, in terms of the activity concentration index $(I)$ or the radium equivalent activity (Ra-eq), is extremely difficult if not impossible (Keller et al., 1987).
Therefore, for such reasons, in the framework of the Buildings sub-project a simplified approach, the Salerno Indoor Radon Emanation Model (S.I.R.E.M.) procedure, to assess indoor radon activity concentrations based upon on-site experimental evaluations of radon emanation by building materials, has been formulated with the aim to realize a tool not only with a scientific valence but also useful and precious for its applications to real situations (Mancini et al., 2012, 2014b).

\section{Conclusions}

Results evidence that to map the radon potential from soil cannot be the only tool, for authorities, to manage the radon issue. The maintenance of the interface soil-building plays one of the most important tool. So, mitigation system and action for new and existing building should focus firstly on this structural part. Apartments and closed spaces sited in the basement and ground floor are very exposed to the radon issue, so the control of indoor concentrations should focus on the lower rooms of a building. The respect of the limits in those places is precautional enough to assure, as first level of analysis, the same at the upper levels, even if in urban areas this assumption could not be respected because of the low ventilation rates which increase the effect of the contribution due to exhalation by building materials.

The categorization of buildings (according the foundation type, materials, number of floors) show how it is possible to identify a peculiar behaviour for each construction-type and so try to build up a performance indicator for different kind of construction, in term of response to the potential radon from soil. So, it could be very interesting to propose in a future work, an indicator of the building performances as useful tool, for authorities, to recognise constructions potentially more exposed to high indoor radon activity concentrations and for professional to support the design of constructions. Statistical analyses could be useful for this purpose, too. 
Data availability. Data are not publicly accessible because studies involved third party and authors have not been authorized to release them.

Author contributions. MG conceived the idea of the presented work. SM wrote the manuscript and processed the experimental data. MG, DG and AC supervised the findings of this work. All authors discussed the results and contributed to the final version of the paper. All authors took part at the reported RAD Campania project. All authors provided critical feedback and helped shape the analysis and paper.

Competing interests. The authors declare that they have no conflict of interest.

Special issue statement. This article is part of the special issue "Understanding volcanic processes through geophysical and volcanological data investigations: some case studies from Italian sites (EGU2019 GMPV5.11 session, COV10 S01.11session)". It is not associated with a conference.

Review statement. This paper was edited by Enza De Lauro and reviewed by two anonymous referees.

\section{References}

ANPA: Il Sistema informative territoriale per la valutazione del potenziale di esalazione di Radon dal suolo, ANPA-RT-00009, ISBN 88-448-0284-8, available at: https://inis.iaea.org/ collection/NCLCollectionStore/_Public/32/007/32007841.pdf (last access: March 2020), 2000 (in Italian).

Baskaran, M.: Radon: A Tracer for Geological, Geophysical and Geochemical Studies, Springer Geochemistry, ISBN 978-3-31921329-3 (eBook), https://doi.org/10.1007/978-3-319-21329-3, 2016.

Biallo, G.: Introduzione ai Sistemi Informativi Geografici, MondoGIS Editore, Roma, 2005 (in Italian).

Blasi, C., Guida, D., Siervo, V., Paolanti, M., Michetti, L., Capotorti, C., and Smiraglia, D.: An integrated, hierarchical, multiscale, gis_based approach to defining and mapping the landscape of Italy, EGU General Assembly 2007, EGU2007-A-10822, 2007.

Bochicchio, F., Campos Venuti, G., and Nuccetelli, C.: Results of the representative Italian national survey on radon indoors, Health Phys, 71, 741-748, https://doi.org/10.1097/00004032199611000-00016, 1996.

Bossew, P., Cinelli, G., Ciotoli, G., Crowley, Q. G., De Cort, M., Elío Medina, J., Gruber, V., Petermann, E., and Tollefsen, T.: Development of a Geogenic Radon Hazard Index - Concept, History, Experiences, Int. J. Environ. Res. Pu. He., 17, 4134, https://doi.org/10.3390/ijerph17114134, 2020.

Buttafuoco, G., Tallarico, A., and Falcone, G.: Mapping Soil Gas Radon Concentration: A Comparative Study of Geo- statistical Methods, Environ. Monit. Assess., 131, 135-151, https://doi.org/10.1007/s10661-006-9463-7, 2007.

Ciotoli, G., Voltaggio, M., Tuccimei, P., Soligo, M., Pasculli, A., Beaubien, S. E., and Bigi, S.: Geographically weighted regression and geostatistical techniques to construct the geogenic radon potential map of the Lazio region: A methodological proposal for the European Atlas of Natural Radiation, J. Env. Rad., 166, 355375, https://doi.org/10.1016/j.jenvrad.2016.05.010, 2017.

Cuomo, A.: The contribute of the Hydro-Geomorphology in the evaluation of the flood discharge in Campania Region, PhD Thesis in Environmental Civil Engineering, University of Salerno, Italy, 2012.

Cuomo, A., Guida, D., Guida, M., Siervo, V., and Mancini, S.: Radon-Prone areas assessment in Campania Region, Italian Radon and Norm Workshop, Research and Advances on Radon and Norm Applications, 14-15, 6-7, ISBN 978-88-907281, 2015.

De Lauro, E., De Martino, S., Falanga, M., and Palo, M.: Modelling the macroscopic behaviour of Strombolian explosions at Erebus volcano, Phys Earth Plan. Int., 176, 174-186, ISSN 0031-9201, https://doi.org/10.1016/J.PEPI.2009.05.003, 2009.

Durridge RAD7: Radon Detector, Owner's Manual, Bedford, MA, USA, 2012.

Falanga, M., De Lauro, E., Petrosino, S., and De Martino, S.: Interaction between seismicity and deformation on different time scales in volcanic areas: Campi Flegrei and Stromboli, Adv. Geosci., 52, 1-8, https://doi.org/10.5194/adgeo-52-1-2019, 2019.

Guida, D., Guida, M. R., Lanzara, R., and Vallario, A.: Methodological and procedural proposals in the Protected Areas Planning: Basic Physical Landscape Unit, Tech. Env. Geology, 50, 137-147, 1994 (bilingual ed.).

Guida, D., Guida, M., Siervo, V., and Guadagnuolo, D.: Radonprone Areas Assessment in Campania Region, Applications of a Hierarchical and Multi-scale Approach to the Environmental Planning, Tech. Env. Geology, XVI, 38-62, 2008.

Guida, D., Guida, M., Siervo, V., and Guadagnuolo, D.: Assessment and Mapping of Radon-prone Areas on a regional scale as application of a Hierarchical Adaptive and Multi-scale Approach for the Environmental Planning. Case Study of Campania Region, Southern Italy, WSEAS Trans. on Syst., 12, 105-120, 2013.

Guida, M., Guida, D., and Cuomo, A.: Space-Time Distribution of Radon-222 from Groundwater-Streamflow-Atmosphere Interactions in the Karst Systems of the Campania Region (Southern Italy), in: Radon: Geology, Environmental Impact and Toxicity Concerns, edited by: Stacks, A. M., 43-98, Nova Publishers Inc., ISBN 978-1-63463-742-8, 2015.

Keller, G., Folkerts, K. H., and Muth, H.: Discussing possible standards of natural radioactivity in building materials, Rad. Env. Biophys., 26, 143-150, 1987.

Hosoda, M., Shimo, M., Sugino, M., Furukawa, M., and Fukushi, M.: Effect of Soil Moisture Content on Radon and Thoron Exhalation, J. Nucl. Sci. Tech., 44, 664-672, 2012.

IEMA (Illinois Emergency Management Agency): Status report for Radon in Illinois, Springfield, Ill.: Illinois Emergency Management Agency, 51 pp., 2006.

Iovine, G., Guagliardi, I., Bruno, C., Greco, R., Tallarico, A., Falcone, G., Lucà, F., and Buttafuoco, G.: Soil-gas radon anomalies in three study areas of Central-Northern 
Calabria (Southern Italy), Nat. Hazards, 91, S193-S219, https://doi.org/10.1007/s11069-017-2839-x, 2018.

Ismail, A. H. and Jaafar, M. S.: Interaction of low-intensity nuclear radiation dose with the human blood: Using the new technique of CR-39NTDs for an in vitro study, Appl. Rad. Isot., 69, 559-566, 2011.

MDS Italian Ministry of Health: Radon National Plan (PNR), http:// www.salute.gov.it/imgs/C_17_pubblicazioni_2436_allegato.pdf (last access: March 2020), 2002 (in Italian).

Mancini, S., Guida, M., Guida, D., and Cuomo, A.: A simplified approach to assess indoor Radon activity concentrations based upon on-site experimental evaluations of Radon exhalation from building materials, RTU 53rd Intl. Sci. Conf., Riga, Latvia, 11116, 2012.

Mancini, S., Guida, M., Guida, D., and Cuomo, A.: Assessing and modeling the contribution to Indoor Radon from the building materials: The S.I.R.E.M Model, Conf. Proc., 7th Int. Conf. on Env. and Geol. Science and Engineering, https://doi.org/10.13140/2.1.3390.7843, 2014a.

Mancini, S., Guida, M., Guida, D., and Cuomo, A.: An overview on the new recommendations and requirements on radon protection (2013/59/Euratom) and the actual state of art: the case-study of the Campania Region, Southern Italy Recent Advances in Civil Engineering and Mechanics, ISBN 978-960-474-403-9 262-271, WSEAS Press, Athens, 2014b.

Mancini, S., Guida, M., Cuomo, A., Guida, D., and Ismail, A. H.: Modelling of indoor radon activity concentration dynamics and its validation through in-situ measurements on regional scale, AIP Conf. Proc., 1982, 020043, https://doi.org/10.1063/1.5045449, 2018.

Nero, A. N.: Earth, Air, Radon and Home, Phys. Today, 42, 32-39, 1989.

Nero, A. N. and Nazaroff, W. W.: Characterising the source of Radon indoors, Rad. Prot. Dos., 7, 23-39, 1984.

Nero, A. N. and Nazaroff, W. W. (Eds.): Radon and Its Decay Products in Indoor Air, Wiley, New York, 518 pp., ISBN 9780471628101, 1988.
Schuman, R. R. and Owen, D. E.: Relationships between Geology, equivalent Uranium concentration, and Radon in soil-gas, Fairfax County, Virginia, US, Geological Survey Open-File Report, 8818, 1988.

Stavitskaya, K., Ryzhakova, N., Udalov, A., and Almyakov, P.: Comparative analysis of the measuring results of the Radon flux density and Ra-226 specific activity for different soils types, AIP Conference Proceedings, 2101, 020013, https://doi.org/10.1063/1.5099605, 2019.

Tollefsen, T., Cinelli, G., and De Cort, M. (Eds.): Special Issue on Geogenic Radiation and its Potential Use for Developing the Geogenic Radon Map, J. Env. Rad., 166, Part 2, 209-416, 2017.

UNSCEAR: UNSCEAR 2000 Report to the General Assembly, with scientific annexes, Volume I: Sources, 1-669, in: United Nations Scientific Committee on the Effects of Atomic Radiation, United Nations, New York, ISBN 92-1-142238-8, 2000.

Vitale, S. and Ciarcia, S.: Tectono-stratigraphic setting of the Campania region (southern Italy), J. Maps, 14, 9-21, https://doi.org/10.1080/17445647.2018.1424655, 2018.

Watson, R. J., Smethurst, M. A., Ganerød, G. V., Finne, I., and Rudjord, A. L.: The use of mapped geology as a predictor of radon potential in Norway, J. Env. Rad., 166, 341-354, https://doi.org/10.1016/j.jenvrad.2016.05.031, 2017.

WHO: WHO handbook on indoor Radon: a public health perspective, World Health Organization, ISBN 9789241547673, 2009.

Wiegand, J.: Radon in urbanen Gebieten - geogene und anthropogene Einflüsse auf das ${ }^{222} \mathrm{Rn}$-Potential am Beispiel des Ruhrgebietes, in: Umweltradioaltivität Geologie und Ökologie im Kontext, edited by: Siehl, A., Berlin, Ernst \& Sohn, 223-232, 1996.

Wiegand, J.: A guideline for the evaluation of the soil radon potential based on geogenic and anthropogenic parameters, Env. Geol. 40, 949-963, https://doi.org/10.1007/s002540100287, 2001.

Yarmoshenko, I. V., Vasilyev, A. V., Onishschenko, A. D., Kiselev, S. M., and Zhulovsky, M. V.: Indoor Radon Problem in Energy Efficient Multi-Storey Buildings, Radiat. Prot. Dosim., 160, 5356, https://doi.org/10.1093/rpd/ncu110, 2014. 